\author{
С.М. Звиглянич ${ }^{1}$, М.П. Ізюмський ${ }^{1}$ Ю.М. Агафонов ${ }^{1}$, А.В. Кошель ${ }^{2}$ \\ ${ }^{1}$ Харківський національний університет Повітряних Сил ім. І. Кожедуба, Харків \\ ${ }^{2}$ Державне космічне агентство України, Головний центр спеціального контролю, Харків
}

\title{
ОЦІНЮВАННЯ ЕФЕКТИВНОСТІ ЗАСТОСУВАННЯ КАСЕТНОЇ БОЙОВОЇ ЧАСТИНИ НА ОСНОВІ ІМІТАЦІЙНОÏ МОДЕЛІ
}

\begin{abstract}
У статті розглядаються підходи до оцінювання ефективності застосування осколково-фугасних боєприпасів, як одних з найбільших і розвиненіших класів боєприпасів, призначених для ураження практично усіх типів цілей. В основу методу оиінювання бойової ефективності осколково-фугасних боєприпасів покладений метод імітації. Таке рішення дозволило відійти від використання складних аналітичних залежностей $i$ значною мірою спростити побудову математичної моделі дї вражаючих елементів цих боєприпасів на об'єкти ураження. Початкові дані, щуо використовуються в моделі, мають ясний фізичний сенс, відображають даний процес ураження цілей, щуо вибрані касетною бойовою частиною, і є обчислюваними. Запропонована імітаційна модель на основі доступних початкових даних дозволяє проводити кількісне оцінювання ефективності застосування касетної бойової частини і тим самим оцінювати рішення, щзо приймаються, при плануванні бойових операчій.
\end{abstract}

Ключові слова: імітаційна модель, касетна бойова частина, уражаючий елемент.

\section{Вступ}

Постановка проблеми. Осколкові і осколковофугасні боєприпаси утворюють один 3 найбільших і розвиненіших класів боєприпасів, призначених для ураження практично усіх типів цілей. Виходячи 3 цього, розробка методичного апарата, що забезпечує їх раціональне застосування, залишається важливим науково-практичним завданням. В першу чергу основною вимогою тут стає доступність початкових даних, при збереженні ними фізичного сенсу і можливості їх отримання в органах бойового управління відповідних рівнів.

При рішенні такого роду завдань, як правило, моделювання стає єдино можливим способом досягнення поставлених цілей.

Аналіз останніх досліджень і публікацій. Аналіз сучасних воєн та збройних конфліктів дає підстави говорити про широке використання касетних бойових частин (КБЧ), як про ефективну сучасну зброю [1-3]. Зокрема, в [4] приведені приклади використання КБЧ для вогневого ураження супротивника, відзначається висока їх продуктивність при досягненні поставлених цілей. Слід зазначити, що практично в усіх публікаціях при розгляді КБЧ, як ефективної зброї, передусім йдеться про їх бойові можливості. Питання ж раціонального застосування КБЧ практично освітлення не знаходить.

Для ухвалення раціональних рішень, спрямованих на підвищення ефективності застосування КБЧ, потрібна кількісна оцінка відповідних рішень, які будуть лежати в основі планування бойових операцій. Вироблення раціональних рішень на застосування КБЧ 3 використанням аналітичних моделей зв'язане зі значними труднощами вибору необхідних початкових даних, що описують досліджуваний процес [5].

Якнайповніша адекватність при дослідженні цих процесів досягається шляхом використання методу імітаційного моделювання [6-9]. Такий підхід дозволяє використовувати доступні початкові дані, що легко обчислюються i мають ясний фізичний сенс.

Метою статті є обгрунтування підходу до оцінювання ефективності застосування касетної бойової частини в осколково-фугасному оснащенні з використанням методу імітації, який дозволяє значно спростити вимоги до початкових даних і тим самим забезпечити застосування цього підходу в усіх ланках органів управління при плануванні бойових операцій.

\section{Виклад основного матеріалу}

У сучасному трактуванні під осколковими боєприпасами (ОБП) розуміються боєприпаси, що уражають ціль високошвидкісним потоком великого числа однотипних інертних уражаючих елементів (УЕ), що розсіюються, як правило, вибухом заряду бризантної вибухової речовини (ВР) [1].

Дамо вербальний опис моделі оцінювання ефективності застосування осколково-фугасного боєприпасу. Нехай об'єкти ураження (ОУ) 
розташовані на місцевості, яку визначимо як зону ураження (ЗУ).

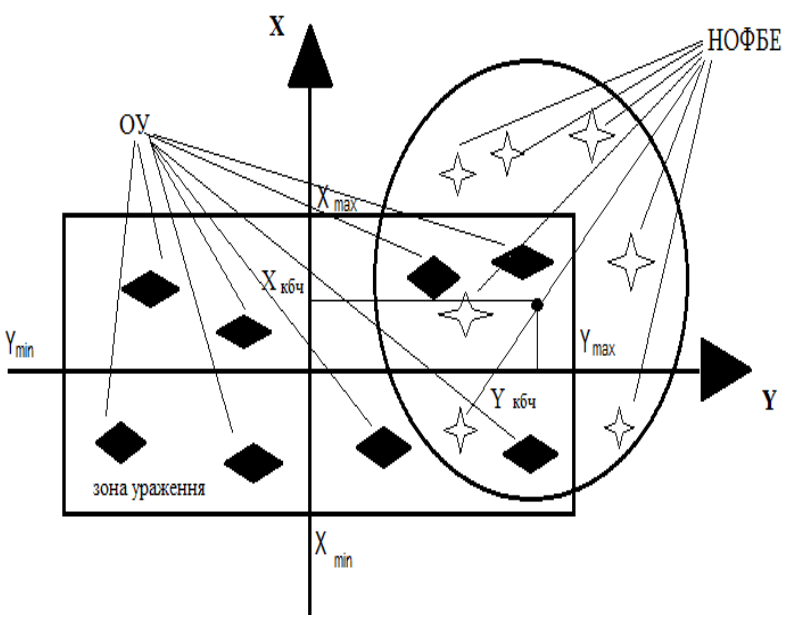

Рис. 1. Зона ураження

Джерело: розроблено авторами

В даному випадку мова ведеться про площинну ціль як сукупність об'єктів, розподілених в межах деякої площі. При цьому удар завдається не по окремих об'єктах, а по усій площі цілі.

Під час вибуху осколкового боєприпасу утворюється осколкове поле - потік осколків, що характеризуються напрямом і швидкістю руху, а також щільністю, тобто кількістю осколків на одиницю площі, яку вони перетинають [2].

Осколки в некерованому осколково-фугасному боєприпасі (НОФБЕ) можуть формуватися:

- природним дробленням;

- заданим дробленням;

- готовими уражаючими елементами (УЕ).

Приймемо наступні допущення:

- НОФБЕ падає вертикально до поверхні;

- НОФБЕ вибухає на заданій висоті $h$;

- осколки НОФБЕ однорідні і розлітаються під заданим кутом $\alpha$;

- кількість осколків кінцева і задана.

Підрив НОФБЕ здійснюється, як правило, на деякій відстані від об'єктів, що уражаються. Політ осколків проходить в повітряному середовищі, що створює опір руху і призводить до падіння їх швидкості на траєкторії [3].

Рух осколка в повітрі розглянемо при наступних допущеннях:

- щільність повітря $\rho_{\theta}$ уздовж траєкторії польоту постійна;

- вплив сили тяжіння незначний;

- площа міделя осколка на траєкторії польоту дорівнює її середньому значенню $\langle S\rangle$;

- коефіцієнт лобового опору $c_{x}$ не залежить від швидкості осколка.

Рівняння руху осколка набуває вигляду:

$$
m \frac{d v}{d t}=-\frac{\rho_{\theta} v^{2}}{2}\langle S\rangle c_{x}
$$

де $v$ - поточна швидкість осколка.

Це рівняння можна представити у вигляді:

$$
\frac{d v}{d t}=-A v^{2}, A=\frac{\rho_{\theta}\langle S\rangle c_{x}}{2 m},
$$

де $A$ - балістичний коефіцієнт, $1 /$ м.

Використовуючи заміну:

$$
\frac{d v}{d t}=\frac{d v}{d x} \frac{d x}{d t}=v \frac{d v}{d x},
$$

можна представити рівняння руху осколка в повітрі у вигляді:

$$
\frac{d v}{d x}=-A v .
$$

3 цього рівняння, зокрема, витікає, що величина $A v \in$ втрата швидкості осколка на шляху в 1метр. Інтегруючи це рівняння за початкової умови $v(0)=v_{0}$, отримуємо:

$$
\ln \frac{v}{v_{0}}=-A x
$$

звідки:

$$
v=v_{0} e^{-A x} .
$$

Цей вираз відомий як закон експоненціального згасання швидкості осколка в польоті [9]. Насправді коефіцієнт лобового опору $c_{x}$ залежить від швидкості і набуває максимального значення при швидкості осколка, рівній швидкості звуку. При цьому допущення того, що коефіцієнт лобового опору $c_{x}$ не залежить від швидкості осколка, $\epsilon$ найгрубішим. Вважатимемо, що вражаючі елементи мають сферичну форму. Тоді функція $c_{x}(v)$ має вигляд [3]:

$$
=\left\{\begin{array}{c}
c_{x}= \\
0.865\left(1+\frac{50}{v}\right) n p u v \geq 550 \frac{M}{c} \\
1.49+0.51 \sin \left(860^{\circ}-350^{\circ} \lg v\right) n p u 150 \leq v<550 \frac{M}{c} \\
0.5 n p u v<150 \frac{M}{c} .
\end{array}\right.
$$

Таким чином, до початкових даних для НОФБЕ віднесемо загальну кількість вражаючих елементів, довжину НОФБЕ, висоту підривання, кут розльоту і початкову швидкість метання.

Розглянемо КБЧ [4]. Як початкові дані, задаються координати іiі розкриття, кількість НОФБЕ і кут їх розльоту. Конкретні значення координат розкриття КБЧ випадкові, розподілені за нормальним законом. Точність КБЧ характеризується середнім квадратичним відхиленням (СКВ) від заданих координат по осях $X, Y, Z-\sigma$ (вважатимемо однаковим по усіх осях). Тоді істинні координати розкриття отримуються шляхом підсумовування заданих ко- 
ординат $X p, Y p, Z p$ із випадковими величинами, що розподілені за нормальним законом із заданим СКВ. На практиці, щоб отримати нормальний розподіл, досить скласти шість екземплярів випадкового числа від 0 до 1 [10]. Сума цих шести чисел:

$$
Z=R_{1}+R_{2}+\ldots+R_{6} .
$$

Вона має розподіл, настільки близький до нормального, що у більшості практичних завдань ним можна замінити нормальне.

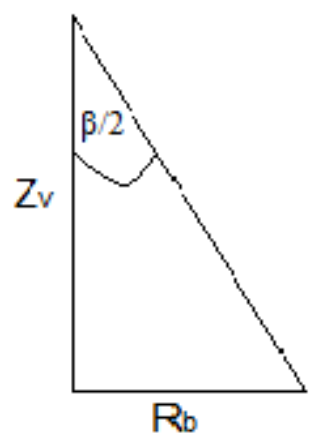

Рис. 2. Радіус кола падіння НОФБЕ

Джерело: розроблено авторами

Для того, щоб отримати істинні координати розкриття КБЧ $X_{v}, Y_{v}, Z_{v}$, необхідно піддати величину $Z$ лінійному перетворенню:

$$
\begin{gathered}
X_{v}=\sigma_{x} \sqrt{2}(Z-3)+X_{p} ; \\
Y_{v}=\sigma_{x} \sqrt{2}(Z-3)+Y_{p} ; \\
Z_{v}=\sigma_{x} \sqrt{2}(Z-3)+Z_{p} .
\end{gathered}
$$

Знаючи кут розльоту бойових елементів $\beta$ і висоту розкриття КБЧ $Z_{\mathrm{v}}$, знайдемо радіус кола падіння НОФБЕ (рис. 2).

$$
R_{b}=Z_{v} \operatorname{tg}(\beta / 2) .
$$

Випадкові координати підривання НОФБЕ знайдемо таким чином (рис. 3). Центр круга співпадає 3 координатами розкриття КБЧ. Отримаємо випадкове число $k$, розподілене за рівномірним законом в інтервалі від 0 до $R_{b}$ і аналогічне число $s$ в інтервалі від 0 до 360. Тоді координати НОФБЕ :

$$
\begin{gathered}
X_{\text {нофбэ }}=X_{v}+k \sin (s) \\
Y_{\text {нофбэ }}=Y_{v}+k \cos (s) .
\end{gathered}
$$

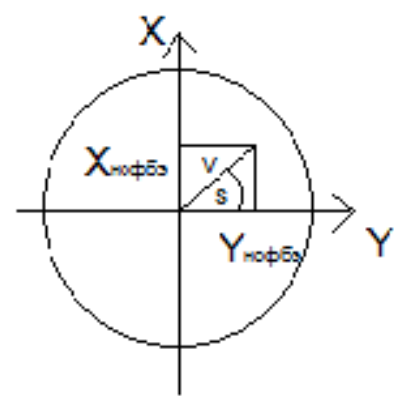

Рис. 3. Координати НОФБЕ

Джерело: розроблено авторами
Уражаюча дія осколка визначається глибиною пробиття перешкоди. Використовуватимемо березанську формулу (при необхідності можуть бути використані і точніші формули) [2]:

$$
h=K \frac{q}{d^{2}} V_{o} \cos \psi_{0},
$$

де $K$-коефіцієнт проникнення, що характеризує властивості перешкоди [м² с/кг];

$$
\begin{aligned}
& q \text { - маса осколка [кг ]; } \\
& d \text { - розмір осколка [м ]; } \\
& V_{o} \text { - швидкість підльоту осколка до перешкоди }
\end{aligned}
$$
$[\mathrm{M} / \mathrm{c}]$

$\psi_{0}$ - кут (від нормалі) зустрічі осколка 3 перешкодою.

Межі зони ураження (рис. 1) визначаються:

- по осі $X$ : від $X_{\min }$ до $X_{\max }$;

- по осі $Y$ : від $Y_{\min }$ до $Y_{\max }$.

Тоді, кожен НОФБЕ з $N$, координати падіння якого $X_{B}, Y_{B}$ лежать в межах по осі $X$ від $X_{\min }$ до $X_{\max }$, по осі $Y$ від $Y_{\min }$ до $Y_{\max }$ потрапив в зону ураження.

Для кожного НОФБЕ введемо характеристичну випадкову величину u, яка набуває значення " 1 ", якщо він потрапив в зону ураження, і значення “ 0 ”, якщо спостерігається промах [11]. Математичне сподівання (МСП) цієї випадкової величини дорівнює:

$$
m_{u}=p_{u 1+\left(1-p_{u}\right) 0=p_{u}} .
$$

У свою чергу, після проведення $K$ реалізацій оцінка цієї імовірності визначається як:

$$
p_{u}^{*}=\frac{S}{K},
$$

де $S$ - число попадань НОФБЕ в зону ураження;

$K$ - число реалізацій імітаційної моделі.

Зробимо підрахунок $\mathrm{m}_{\mathrm{u}}$ для кожного НОФБЕ. 3 урахуванням того, що МСП суми випадкових величин дорівнює сумі їх МСП [12], знайдемо МСП числа НОФБЕ, що потрапили в зону ураження при заданих початкових даних:

$$
m_{\text {нофбе }}=\sum_{i=1}^{N} p_{u i} \text {. }
$$

Нехай число УЕ для НОФБЕ відоме і складає $G$ одиниць. Тоді, в суттєвому наближенні (груба оцінка), на кожен об'єкт ураження припаде число УЕ, яке дорівнює:

$$
g_{\text {oy }}=\frac{m_{\text {нофбе }} G}{O Y_{\Sigma}},
$$

де $O Y_{\Sigma}$ - сумарна кількість об'єктів ураження, розташованих в зоні ураження

Для точнішої оцінки дії НОФБЕ по об'єктах ураження враховуватимемо дію осколкового поля 
кожного НОФБЕ на кожен об'єкт ураження. Для цього необхідно в якості початкових даних задавати координати об'єктів ураження. Після визначення координат підривання НОФБЕ визначимо кількість УЕ, що потрапили в ОУ. Кожен ОУ представляється у вигляді циліндра, основа якого дорівнює площі ОУ, а висота-висоті ОУ,

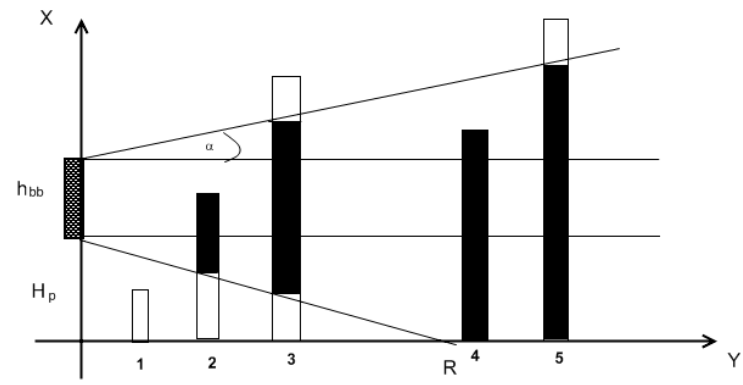

Рис. 4. Формування поля УЕ для НОФБЕ Джерело: відпрацьовано авторами

Введемо позначення:

$h_{0}$ - висота об'єкту;

$h_{b b}$ - довжина НОФБЕ;

$H_{p}$ - висота підривання НОФБЕ;

$R$ - нульовий рубіж нижньої межі поля УЕ;

$\alpha$ - кут розльоту УЕ;

$r_{0}$ - приведений радіус об'єкту;

$S_{p}$ - площа об'єкту, що уражається.

Визначимо верхню межу поля УЕ:

$$
G_{v}=H_{p}+h_{b b}+y_{t} \operatorname{tg} \alpha,
$$

де $y_{t}$-поточна відстань від точки підривання НОФБЕ.

Тепер визначимо нижню межу поля УЕ:

$$
G_{n}=H_{p}-y_{t} \operatorname{tg} \alpha .
$$

Визначимо нульовий рубіж нижньої межі поля УЕ:

$$
R=\frac{H_{p}}{\operatorname{tg} \alpha} .
$$

Розглянемо випадки, коли $R>y_{t}$. На рис. 4 це 1, 2, 3 випадки.

Для випадку $1-G_{n}>h_{0}$. Об'єкт не потрапляє під дію УЕ, $S_{p}=0$.

Випадок $2-G_{v}>h_{0}>G_{n}$.

Випадок $3-h_{0}>G_{v}$.

Якщо $y_{t}>R$, розглядаються випадки 4 i 5 .

Випадок $4-G_{v}>h_{0}$.

Випадок $5-h_{0}>G_{v}$.

Після того, як в об'єкті визначена площа, що вражається, знаходимо число УЕ, що потрапили в неї:

$$
n_{p p}=\left(\frac{S_{p}}{2 \pi y_{t}\left(G_{v}-G_{n}\right)}\right) N_{b b},
$$

де $N_{b b}$ - кількість УЕ в НОФБЕ.

Для кожної одиниці військової техніки введемо стани [2]:

$$
\begin{aligned}
& \text { - знищена; } \\
& \text { - виведена з ладу; } \\
& \text { - подавлена. }
\end{aligned}
$$

Стан “знищена” настає при повному знищенні без можливості відновлення. Стан “виведена з ладу” відповідає стану, коли для відновлення потрібно капітальний (середній) ремонт, що проводиться спеціалізованими органами. Стан “подавлена" відповідає стану, коли бойова готовність відновлюється силами бойового розрахунку при виході з бою.

Для кожного зразка військової техніки виділимо чотири області. Перша область - попадання в яку призводить до знищення. Друга область - попадання в яку виводить техніку з ладу. Третя область - попадання в яку призводить до подавлення. I четверта область - попадання в яку не критично. Нехай перша область складає 10\% від загального об'єму зразка техніки, друга $-20 \%$, третя, $-40 \%$, і четверта $-30 \%$ відповідно (рис. 5)

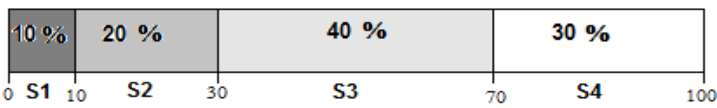

Рис. 5. Зони ураження

Джерело: розроблено авторами

Задамо кількість УЕ, що потрапили в зразок військової техніки. Стільки ж разів звернемося до датчика випадкових чисел рівномірно розподілених на відрізку від 0 до 100. Якщо датчик видає значення в інтервалі від 0 до 10, то вважаємо, що УЕ потрапив в першу область. Якщо значення датчика лежить в інтервалі від 11 до 30, то УЕ потрапив в другу область. Аналогічно, значення лічильника в інтервалі від 31 до 70 відповідає попаданню УЕ в третю область і при значенні лічильника в межах від 71 до 100 означає попадання в четверту область. Кожне попадання у відповідну область підраховується в лічильниках $S_{1}, S_{2}, S_{3}, S_{4}$. Якщо в зразок військової техніки потрапило $g_{\text {oy }}$ УЕ, тоді оцінка МСП числа УЕ, що потрапили в першу область, складає:

$$
m_{1}=\frac{S_{1}}{g_{o y}},
$$

в другу:

$$
m_{2}=\frac{S_{2}}{g_{o y}},
$$

в третю:

$$
m_{3}=\frac{S_{3}}{g_{o y}},
$$


і в четверту:

$$
m_{4}=\frac{S_{4}}{g_{o y}} .
$$

Розрахована по формулі (9) кількість УЕ $g_{\text {oy }}$, що потрапили в ОУ, дозволяє визначити, в яку 3 областей потрапив хоча б один УЕ. Якщо енергетика УЕ дозволяє пробити ОУ, то останній переходить у відповідний стан. Тобто, якщо при попаданні $g_{o y}$ УЕ $m_{1} \geq 1$ і енергетика УЕ дозволяє пробити ОУ, то він переходить в стан “знищений”. Якщо $m_{1}<1$, то розглядаємо значення $\mathrm{m}_{2}$. При $m_{2} \geq 1$ і пробитті ОУ, останній переходить в стан “виведений з ладу”. Якщо і $m_{2}<1$, то, аналогічно, послідовно розглядається $m_{3}, m_{4}$ і ОУ переходить у відповідний стан.

До початкових умов моделювання віднесемо межі зони ураження, кількість і розташування на місцевості (координати) об'єктів ураження, їх геометричні розміри і характеристики міцності, характеристики точності КБЧ, кількість НОФБЕ, кількість УЕ. В якості критерію оцінювання ефективності застосування КБЧ в даній операції може використовуватися вираз за заданих початкових умов:

$$
W_{y} \geq W_{y}^{T}
$$

де $W_{y}$-кількість знищених об'єктів в операції за результатами моделювання;

$W_{y}^{T}$ - кількість об'єктів, які потрібно знищити.
Ця оцінка може бути уточнена за рахунок введення обмеження на час відновлення бойової готовності об'єктів, які виведені з ладу і подавлені.

$$
W_{y} \geq W_{y}^{T}
$$

при $T_{\Sigma}^{B} \geq t_{B} W_{6}+t_{n} W_{n}$,

де $t_{b}$ - середній час, потрібний на відновлення об'єкту, який виведений з ладу;

$W_{6}$ - кількість виведених з ладу об'єктів;

$t_{n}$ - средній час відновлення подавленого об'єкту;

$W_{n}$ - кількість подавлених об'єктів.

\section{Висновки}

Розглянутий вище підхід, побудований на методі імітації, з використанням ряду емпіричних залежностей, дає можливість визначити основні вимоги до осколково-фугасних боєприпасів для ефективного їх застосування по заданих об'єктах ураження, а також проводити кількісне оцінювання ефективності застосування касетної бойової частини i, таким чином, оцінювати рішення, що приймаються під час планування бойових операцій. При варіюванні вказаними параметрами з'являється можливість прийняття раціонального рішення на застосування КБЧ в конкретних умовах ведення бойових дій. Така імітаційна модель може бути використана в системі підтримки ухвалення рішень командиром відповідного рівня.

\section{Список літератури}

1. Селиванов В.В. Боеприпасы. Т1 / под общей ред. В.В.Селиванова. - М.: МГТУ им. Н.Э. Баумана, 2016. $506 \mathrm{c}$.

2. Балаганский И.А. Действие средств поражения и боеприпасов / И.А. Балаганский, Л.А. Мержиевский. - 2-е изд., испр. и доп. - Новосибирск: Изд-во НГТУ, 2017. - 408 с.

3. Средства поражения и боеприпасы / А.В. Бабкин, В.А. Велданов, Е.Ф. Грязнов и др.; под общ.ред. В.В. Селиванова. - М.: МГТУ им. Н.Э.Баумана, 2008. - 984 с.

4. Матвеев С.В. Взгляды на проблему использования кассетных боеприпасов за рубежом / С.В. Матвеев // Зарубежное военное обозрение. - 2010. - № 2. - С. 54-59.

5. Бойко А.А. Способ аналитического моделирования боевых действий / А.А. Бойко // Системы управления, связи и безопасности. - 2019. - № 2. - С. 1-27.

6. Моделирование систем и процессов / В.Н. Волкова, Г.В. Горелова, В.Н. Козлов и др.; под ред. В.Н. Волковой, В.Н. Козлова. - М.: Издательство Юрайт, 2015. - 449 с.

7. Каталевский Д.Ю. Основы имитационного моделирования и системного анализа в управлении / Д.Ю. Каталевский. - М.: Дело, 2015. - 496 с.

8. Строгалев В.П. Имитационное моделирование / В.П. Строгалев, И.О. Толкачева // М.: Изд-во МГТУ им. Н.Э. Баумана. 2015. - 296 с.

9. Резяпов Н. Имитационная система моделирования боевых действий JWARS BC CША / Н. Резяпов, С. Чеснаков, М. Инюхин // Зарубежное военное обозрение. - 2008. - № 11. - С. 27-32.

10. Писарук Н.Н. Исследование операций / Н.Н. Писарук. - Минск: БГУ, 2015. - 304 с.

11. Самойленко Н.И. Теория вероятностей / Н.И. Самойленко, А.И. Кузнецов, А.Б. Костенко. - Х.: Издательство "НТМТ”, ХНАГХ, 2009. - 200 c.

12. Вентцель Е.С. Теория вероятностей и ее инженерные приложения / Е.С. Вентцель, Л.А. Овчаров. 3-е изд., перераб. и доп. - М.: Академия, 2003. - 464 с. 


\section{References}

1. Selivanov, V.V. (2016), "Boyepripasy" [Ammunition], MGTU im. N.E.Bauman, Moscow, 506 p.

2. Balaganskiy, I.A. and Merzhiyevskiy, L.A. (2017), "Deystviye sredstv porazheniya i boyepripasov" [The effect of weapons and ammunition], NSTU Publishing House, Novosibirsk, 408 p.

3. Babkin, A.V.,Veldanov, V.A. and Gryaznov, Ye.F. (2008), "Sredstva porazheniya i boyepripasy" [Means of destruction and ammunition], MGTU im. N.E.Bauman, Moscow, $984 \mathrm{p}$.

4. Matveyev, S.V. (2010), "Vzglyady na problemu ispol'zovaniya kassetnykh boyepripasov za rubezhom" [Views on the problem of using cluster munitions abroad], Foreign Military Review, No. 2, pp. 54-59.

5. Boyko, A.A. (2019), "Sposob analiticheskogo modelirovaniya boyevykh deystviy" [The method of analytical modeling of military operations], Management, communication and security systems, No. 2, pp 1-27.

6. Volkova, V.N., Gorelova, G.V. and Kozlov, V.N. (2015), “Modelirovaniye sistem i protsessov" [Modeling systems and processes], Publishing house Yurayt, Moscow, $449 \mathrm{p}$.

7. Katalevskiy, D.Yu (2015), "Osnovy imitatsionnogo modelirovaniya i sistemnogo analiza v upravlenii" [The basics of simulation and system analysis in management], Delo, Moscow, 96 p.

8. Strogalev, V.P. and Tolkacheva, I.O. (2015), "Imitatsionnoye modelirovaniye" [Simulation modeling], MGTU im. N.E.Bauman, Moscow, 296 p.

9. Rezyapov, N., Chesnakov, S. and Inyukhin, M. (2008), "Imitatsionnaya sistema modelirovaniya boyevykh deystviy JWARS VS SSHA" [The simulation system of combat modeling JWARS US Armed Forces], Foreign Military Revie, No. 11, pp. 27-32.

10. Pisaruk, N.N. (2015), "Issledovaniye operatsiy" [Operations Research], BSU, Minsk, 304 p.

11. Samoylenko, N.I., Kuznetsov, A.I. and Kostenko, A.B. (2009), "Teoriya veroyatnostey" [ Probability Theory], Publishing house "NTMT", KNAGH, Kharkiv, 200 p.

12. Venttsel', Ye.S. and Ovcharov, L.A. (2003), "Teoriya veroyatnostey i yeye inzhenernyye prilozheniya" [Probability Theory and Its Engineering Applications], Academy, Moscow, 464 p.

Надійшла до редколегії 02.03.2020

Схвалена до друку 12.05.2020

\section{Відомості про авторів:}

\section{Звиглянич Сергій Миколайович}

кандидат технічних наук старший науковий співробітник старший науковий співробітник

Харківського національного університету

Повітряних Сил ім. I. Кожедуба,

Харків, Україна

https://orcid.org/0000-0003-2419-8093

\section{Ізюмський Микола Павлович}

науковий співробітник

Харківського національного університету

Повітряних Сил ім. І. Кожедуба,

Харків, Україна

https://orcid.org/0000-0002-2752-239X

\section{Агафонов Юрій Миколайович}

кандидат технічних наук доцент

головний науковий співробітник

Харківського національного університету

Повітряних Сил ім. I. Кожедуба,

Харків, Україна

https://orcid.org/0000-0001-6872-5268

\section{Кошель Анатолій Васильович}

кандидат технічних наук доцент начальник АСП “Харків"

Державного космічного агентства України Головного центру спеціального контролю, Харків, Україна

https://orcid.org/0000-0003-1887-3574

\section{Information about the authors:}

\section{Sergey Zviglyanich}

Candidate of Technical Sciences Senior Research Associate

Senior Research Associate

of Ivan Kozhedub Kharkiv

National Air Force University,

Kharkiv, Ukraine

https://orcid.org/0000-0003-2419-8093

\section{Nikolay Izumskiy}

Research Associate

of Ivan Kozhedub Kharkiv

National Air Force University,

Kharkiv, Ukraine

https://orcid.org/0000-0002-2752-239X

Yurii Agafonov

Ph.D. in Engineering Science Associate Professor

Chief Research Associate

of Ivan Kozhedub Kharkiv

National Air Force University,

Kharkiv, Ukraine

https://orcid.org/0000-0001-6872-5268

\author{
Anatoliy Koshel \\ Candidate of Technical Sciences \\ Associate Professor \\ Head ASP "Kharkiv" \\ State Spase Agency of Ukraine Center of Special Control \\ Kharkiv, Ukraine \\ https://orcid.org/0000-0003-1887-3574
}




\title{
ОЦЕНИВАНИЕ ЭФФЕКТИВНОСТИ ПРИМЕНЕНИЯ КАССЕТНОЙ БОЕВОЙ ЧАСТИ НА ОСНОВЕ ИМИТАЦИОННОЙ МОДЕЛИ
}

\author{
С.Н. Звиглянич, Н.П. Изюмський, Ю.Н. Агафонов, А.В. Кошель
}

В статье рассматриваются подходы к очениванию эффективности применения осколочно-фугасных боеприпасов, как одних из самых обширных и развитых классов боеприпасов, предназначенных для поражения практически всех типов иелей. В основу метода оценивания боевой эффективности осколочно-фугасных боеприпасов положен метод имитации. Такое решение позволило уйти от использования сложных аналитических зависимостей и, в значительной мере, упростить построение математической модели воздействия поражающих элементов данных боеприпасов на объекты поражения. Используемые в модели исходные данные имеют ясный физический смысл, отражают рассматриваемый процесс поражения выбранных целей кассетной боевой частью и являются вычислимыми. Предложенная имитационная модель на основе доступных исходных данных позволяет проводить количественную оценку эффективности применения кассетной боевой части и, тем самым, оценивать принимаемые решения при планировании боевых операций.

Ключевые слова: имитационная модель, кассетная боевая часть, поражающий элемент.

\section{ESTIMATION OF EFFICIENCY OF APPLICATION OF CASSETTE BATTLE PART ON THE BASIS OF SIMULATION MODEL}

\author{
S. Zviglyanich, N. Izumskiy, Yu. Agafonov, A. Koshel
}

The article discusses approaches to assessing the effectiveness of the use of high-explosive fragmentation ordnance as one of the most extensive and developed classes of ammunition designed to destroy almost all types of targets. The method for evaluating the combat effectiveness of high-explosive fragmentation ordnance is based on a simulation method. Such a solution allowed us to get away from using complex analytical dependencies and to greatly simplify the construction of a mathematical model of the impact of the striking elements of these munitions on targets. As an ammunition, the model describes the most effective ammunition in the form of a cluster warhead equipped with unguided high-explosive fragmentation combat elements. The separation point of the cluster warhead and the coordinates of the explosion of unguided high-explosive fragmentation ordnance are considered in the model as random variables with a normal distribution law. Accuracy characteristics of both the cluster warhead itself and unguided high-explosive fragmentation munitions are expressed in terms of the corresponding standard deviations. Damaged objects in the process of striking can go into the following states: "destroyed"; "disabled"; "suppressed". The state "destroyed" occurs with complete destruction without the possibility of recovery. The state "disabled" corresponds to the state when a major (average) repair is required by the specialized authorities for restoration. The "suppressed" state corresponds to the state when the combat readiness is restored by the forces of combat crew when leaving the battle. To determine the corresponding state in each lesion, four areas are distinguished. The first area - hitting and breaking through leads to destruction. The second area - hitting and breaking through breaks the equipment out of order. The third area - hitting and breaking through leads to suppression. And the fourth area-hitting and breaking through is not critical. Based on the size of these areas, it is determined for each of them the number of striking elements that hit the object, at which at least one of the striking elements falls into the corresponding area. In each implementation of the simulation model, the process of launching a cluster warhead taking into account the accuracy characteristics at a certain point in space is played out. For each unguided high-explosive fragmentation ordnance, the fact of its falling into the area of location of the objects of destruction is established. Knowing the number of such uncontrolled high-explosive fragmentation warheads that hit and the number of destructive elements in each of them, the total number of destructive elements affecting the targets is determined. Having determined the average number of damaging elements acting on the affected objects, the number of objects in this implementation is calculated that received the corresponding defeat, expressed through the states discussed above. After carrying out a given number of implementations of the simulation model, the processing of the obtained statistical material is carried out. In the end result, the estimate of the mathematical expectation of the number of objects of damage that received such degrees of damage as "destroyed", "incapacitated," "suppressed" is determined. For a more accurate assessment of the effectiveness of the use of a cluster warhead, it is proposed to simulate the explosion points of each unguided high-explosive fragmentation warhead and determine the number of damaging elements that fall into each described object of destruction. Further, similarly, it is determined that the object of the lesion received an appropriate degree of lesion. The model does not take into account the fact of accumulation of damage received by the target. It's just that each implementation takes into account the maximum damage received in the process of considering the impact on it by each unguided high-explosive fragmentation warhead. The proposed simulation model based on the available source data allows us to quantify the effectiveness of the use of cluster warheads and thereby evaluate the decisions made when planning combat operations.

Keywords: simulation model, cluster warhead, striking element. 